\title{
A robust approach to parameterize dislocation glide energy barriers in FCC metals and alloys
}

\author{
Farhan Ashraf $^{1, *}$ (D) and Gustavo M. Castelluccio ${ }^{1}$ \\ ${ }^{1}$ School of Aerospace, Transport and Manufacturing, Cranfield University, Bedfordshire MK43 OAL, UK
}

Received: 15 January 2021

Accepted: 21 July 2021

Published online:

3 August 2021

(C) The Author(s) 2021

\begin{abstract}
The mechanical response of metallic materials is controlled by multiple deformation mechanisms that coexist across scales. Dislocation glide is one such process that occurs after bypassing obstacles. In macroscopic well-annealed single-phase metals, weak obstacles such as point defects, solid solution strengthening atoms, short-range dislocation interactions, and grain boundaries control dislocation glide by pinning the scarce dislocation density. This work investigates the dislocation glide energy barrier in face-centered cubic (FCC) metallic materials by considering a crystal plasticity model that computes the yield strength as a function of temperature. The dislocation glide energy barrier is parameterized by three different formulations that depend on two parameters. A Monte Carlo analysis randomly determines all other coefficients within uncertainty bounds identified from the literature, followed by fitting the two energy barrier parameters to experimental data. We consider ten FCC materials to demonstrate that the methodology characterizes robustly the dislocation glide energy barrier used by crystal plasticity models. Furthermore, we discovered a correlation between the glide barrier and the stacking fault energy that can be used as a basis to infer the glide activation energy.
\end{abstract}

Handling Editor: Avinash Dongare.

Address correspondence to E-mail: f.ashraf@cranfield.ac.uk

E-mail Address: castellg@cranfield.ac.uk 


\section{GRAPHICAL ABSTRACT}

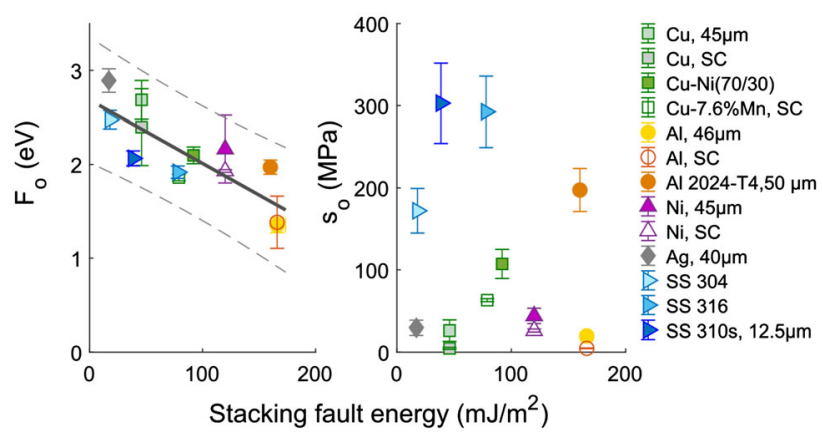

\section{Introduction}

Strain hardening in single-phase metallic materials is controlled by the production, migration, and annihilation of defects [1]. Vacancies, interstitials or substitutional atoms, dislocations, and grain boundaries contribute to hardening by creating barriers that need to be overcome by dislocations. Point obstacles, such as isolated solute atoms, interstitials, and vacancies, correspond to weak obstacles; forest dislocations are medium strengthening obstacles, while precipitates are strong obstacles [2]. In engineering alloys, all obstacles coexist and contribute to macroscopic strength. However, strengthening in well-annealed single-phase metals is controlled by weak obstacles.

Molecular dynamics calculations have recently [3-5] been employed to estimate the dislocation glide energy barrier in simple metallic systems. For example, Esteban et al. [4] characterized the glide energy barrier from Guinier-Preston zones using molecular dynamics simulations. Similarly, Dong et al. [6] simulated the strengthening associated with the collaborative response of multiple obstacles in metals. However, the small scale and high deformation rate of atomistic models make it difficult to transfer quantitative data to coarser crystal plasticity models. Furthermore, the combinatorial nature of atomic configurations in alloys is still unresolved with molecular dynamics, whose results are often valid for a specific strengthening mechanism with a certain atomic order.
Other efforts $[7,8]$ have quantified the glide energy barrier by analyzing yield stress experimental data. For example, Frost and Ashby [2] characterized the dislocation glide barrier by studying the yield stress dependence on temperature. Building on this idea, Balasubramanian and Anand [9] proposed an elastoviscoplastic model to parameterize thermal and athermal hardening using aluminum yield stress data at different temperatures. These approaches relied on constitutive models that do not distinguish strengthening from point defects, dislocation, and grain boundaries, which operate at different length scales. A further limitation of these efforts is their simultaneous estimation of multiple parameters, which sums up the uncertainty from various mechanisms across different scales. Indeed, not all mechanisms become active upon a change in loading conditions (e.g., monotonic, cyclic, etc.), so the results are not fully transferable across scales, models, and loading conditions.

This paper extends the work from Balasubramanian and Anand [9] by parameterizing multiple strengthening mechanisms independently, whose uncertainty is estimated from modeling and experimental data. These parameterizations inform Monte Carlo simulations that fit a crystal plasticity physicsbased constitutive model to yield stress data at different temperatures. The approach results in a robust methodology to parameterize the dislocation glide barrier and can be used to inform crystal plasticity models. Moreover, the analysis of multiple FCC metals and alloys demonstrates a correlation between 
the glide barrier activation energy and the intrinsic stacking fault energy (SFE).

\section{Mechanics of dislocation glide}

Eyring [10] pioneer work recognized that inelastic deformation conforms to the principles of transition state theory and hypothesized that stochastic atomic perturbations control dislocations glide. Gibbs [11] further proposed that the probability of a dislocation to overcome an obstacle can be computed as,

$\Gamma=v \exp \left(\frac{-\Delta G(\tau)}{k_{B} T}\right)$

in which $v$ is the attempt frequency, $k_{B}$ is the Boltzmann constant, $T$ is the temperature, and $\Delta G$ is the Gibbs free activation energy required by a dislocation to glide, which depends upon the local shear stress $(\tau)$. Furthermore, the probability of gliding can be related to the shear rate $\left(\dot{\gamma}^{\alpha}\right)$ along slip system $\alpha$ following Orowan's model [12],

$\dot{\gamma}^{\alpha}=\rho^{\alpha} b l_{v} v \exp \left(\frac{-\Delta G(\tau)}{k_{B} T}\right)$

in which $\rho^{\alpha}$ is the dislocation density on the primary slip system $\alpha, b$ is the Burgers vector, and $l_{v}$ is the average spacing between dislocation obstacles.

The mathematical nature of the Gibbs free activation energy is still a matter of debate, and different formulations have been proposed. One common approach quantifies $\Delta G$ by defining a dislocationobstacle interaction potential, whose first derivate corresponds to the force $(F)$ as a function of the distance traveled by the dislocation [11]. Several approaches including Seeger [13], Fleischer [14], and Mott and Nabarro [15] independently proposed different interaction potentials based on exponential, local tetragonal distortion, and sinusoidal formulations, respectively. These phenomenological interaction potentials can be generalized as,

$\Delta G=F_{0}\left(1-\left(\frac{\tau}{s_{0}}\right)^{p}\right)^{q}$

in which $F_{0}$ is the activation energy at $0 \mathrm{~K}, s_{0}$ is the thermal stress, and $p$ and $q$ are profile parameters that range between 0 to 1 and 1 to 2 , respectively.

A second common approach [16] quantifies the Gibbs free energy by subtracting the work carried out by the stress field $(\tau \Delta V)$ to the Helmholtz free energy $(\Delta F)$,

$\Delta G=\Delta F-\tau \Delta V$

in which $\Delta V$ corresponds to the thermodynamic activation volume. More recently, Langer [17] argued about the lack of physical understanding of the origin of both these mathematical formulations and proposed a thermodynamically consistent approach,

$\Delta G=F_{0}^{*} \exp \left(-\frac{\tau}{s_{0}^{*}}\right)$

in which $F_{0}^{*}$ is the pinning energy at zero stress and $s_{0}^{*}$ is the Taylor stress according to Langer.

Equation (1) represents the thermally activated plastic deformation and assumes that the Gibbs energy does not depend on the temperature. Hence, parameters in Eqs. (3)-(5) should also be temperature independent. As noted by Kocks et al. [18], the temperature independence of parameters is a reasonable assumption for glide resistance profiles without a plateau, which is the case for most FCC metals and alloys up to moderate temperatures.

Equations (3)-(5) are up to a certain degree equivalent, with the exception that Eq. (3) requires four parameters rather than two. A larger number of parameters provides further flexibility for representing nonlinear responses but makes the estimation of the parameters more challenging. Hence, we first focus on determining the parameters for the hardest case (Eq. (3)), which has been extensively employed to model strain hardening in FCC single and polycrystals $[9,19,20]$.

Following on, the combination of Eqs. (2) and (3) leads to [19],

$\dot{\gamma}^{\alpha}=\rho^{\alpha} b l_{v} v \exp \left[-\frac{F_{0}}{k_{B} T}\left\{1-\left(\frac{\tau_{\text {eff }}^{\alpha}}{s_{0} \frac{\mu}{\mu_{0}}}\right)^{p}\right\}^{q}\right]$

in which $\tau_{\mathrm{eff}}^{\alpha}$ is the effective shear stress, while $\mu$ and $\mu_{0}$ correspond to the shear modulus at temperatures $T$ and $0 \mathrm{~K}$. Furthermore, $\tau_{\text {eff }}^{\alpha}$ depends on the local resolved shear stress, $\left(\tau^{\alpha}\right)$, the athermal stress $\left(S^{\alpha}\right)$, and the long-range intragranular back stress $\left(B^{\alpha}\right)$,

$\tau_{\mathrm{eff}}^{\alpha}=\left\langle\left|\tau^{\alpha}-B^{\alpha}\right|-S^{\alpha}\right\rangle$

We estimate the strength of dislocation pinning by point obstacles [21] (vacancies, impurities) by considering the deformation up to plastic yield. Indeed, other mechanisms (e.g., cross-slip or long-range back 
stresses) are less likely to be dominant at the onset of plastic yield in well-annealed materials. Even when many mechanisms are not active, the yield stress still carries a significant variability that should be taken into consideration. Thus, we reorganized Eq. (6) in terms of the yield stress as follows,

$\sigma_{y}^{\alpha}=\left[S^{\alpha}+\left(s_{o} \frac{\mu}{\mu_{0}}\right)\left[1-\left\{-\frac{k_{B} T}{F_{0}} \ln \left(\frac{\dot{\gamma}_{y}^{\alpha}}{\rho^{\alpha} b l_{v} v}\right)\right\}^{\frac{1}{q}}\right]^{\frac{1}{p}}\right] \times C_{f}$

Here $\dot{\gamma}_{y}^{\alpha}$ is the strain rate at yield stress and $C_{f}$ is a factor that projects the mean shear stress into normal stress [22]. This parameter has a value that typically ranges from the Taylor factor (3.06) as an upper bound and to the Sachs factor (2.238) as a lower bound. This range represents an independent and approximate estimate of the conversion factor and accounts for some crystallographic variability.

The athermal stress in Eq. (8) follows [19],

$S^{\alpha}=\alpha_{L E} \frac{\mu b}{2 d_{\text {struc }}}+\mu b \sqrt{A_{i i} \rho^{\alpha}}$

in which the first term conveys the stress required to bow-out dislocations and dislocation interaction stress. Here, $\alpha_{L E}$ corresponds to the line-energy scaling factor, while $A_{i i}$ is the interaction coefficient. In well-annealed metals, the contribution from latent hardening on the stress at the onset of plastic deformation (i.e., at $0.2 \% \epsilon_{p}$ ) is negligible [23]. Dislocation production on secondary slip systems promotes dislocation substructures and limits the dislocation free path of the dominant slip. Hence, the dislocation substructure length scale $d_{\text {struc }}$ in Eq. (9) follows a similitude relation [24] as,

$d_{\text {struc }}=K_{\text {struc }} \frac{\mu b}{\tau}$

where $K_{\text {struc }}$ is the similitude coefficient. At yielding, macroscopic annealed materials have sparse dislocations, and the contribution of the first term is negligible. (We assume crystals over $1 \mu \mathrm{m}$ in size to neglect dislocation starvation hardening [25].) Instead, strengthening comes from self-hardening interactions.

The dislocation density at yield follows the initial density after annealing $\left(\rho_{o}{ }^{\alpha}\right)$ and the density increase upon loading up to yield $\left(\Delta \rho_{y}{ }^{\alpha}\right)$,
$\rho^{\alpha}=\rho_{o}^{\alpha}+\Delta \rho_{y}^{\alpha}$

Hansen [26] demonstrated that the increase in dislocation density depends on grain size, which is due to differences in the dislocations' mean free paths. Hence, $\Delta \rho_{y}{ }^{\alpha}$ can be computed as,

$\Delta \rho_{y}^{\alpha}=\frac{K_{m} \Delta \gamma^{\alpha}}{b d_{m}}$

where the dislocations' production scaling parameter $\left(K_{m}\right)$ has a value that ranges between 1 and 4 [26-29]. For well-annealed materials, the mean free path $\left(d_{m}\right)$ can be estimated as half the grain size [30], which corresponds to the average distance a dislocation can travel before encountering a grain boundary. Since the mean free path affects the calculation of the dislocation density and strengthening, Eq. (12) introduces a dependence on the grain size and accounts for Hall-Petch effects.

Finally, the jump frequency follows,

$v=\frac{k_{B} T}{h}$

which comes from Eyring's reaction rate theory [31] and corresponds to the atomic attempt frequency between $10^{10}$ and $10^{12} \mathrm{~s}^{-1}$. The obstacle spacing has a significant role in bypassing the energy barrier during thermal activation because a single event can create a cascade of unpinning events [32].

By combining Eqs. (9)-(13) with Eq. (8), we obtain

$$
\begin{aligned}
\sigma_{y}^{\alpha}(T)= & {\left[\mu b \sqrt{A_{i i}\left(\rho_{o}^{\alpha}+\frac{K_{m} \Delta \gamma^{\alpha}}{b d_{m}}\right)}+\left(s_{o} \frac{\mu}{\mu_{0}}\right)\right.} \\
& {\left[1-\left\{-\frac{k_{B} T}{F_{0}} \ln \left(\frac{\dot{\gamma}_{y}^{\alpha}}{\left.\left.\left.\left.\left(\rho_{o}^{\alpha}+\frac{K_{m} \Delta \gamma^{\alpha}}{b d_{m}}\right) b l_{v} \frac{k_{B} T}{h}\right)\right\}^{\frac{1}{\rho}}\right]^{\frac{1}{p}}\right]}\right.\right.\right.} \\
& \times \frac{2 C_{f} K_{\text {struc }}}{\left(2 K_{\text {struc }}-\alpha_{L E}\right)}
\end{aligned}
$$

which relates the yield stress with the temperature and strain rate. Hence, we can employ this equation to fit experimental data using minimum-square regression to estimate $F_{0}$ and $s_{0}$. For completeness, we apply the same approach but considering Eqs. (4) and (5) to obtain, 


$$
\begin{aligned}
\sigma_{y}^{\alpha}(T)= & {\left[\mu b \sqrt{A_{i i}\left(\rho_{o}^{\alpha}+\frac{K_{m} \Delta \gamma^{\alpha}}{b d_{m}}\right)}\right.} \\
& +\left[\frac{\Delta F}{l_{v} b d}+\left\{\frac{k_{B} T}{l_{v} b d} \ln \left(\frac{\dot{\gamma}_{y}^{\alpha}}{\left.\left(\rho_{o}^{\alpha}+\frac{K_{m} \Delta \gamma^{\alpha}}{b d_{m}}\right) b l_{v} \frac{k_{B} T}{h}\right)}\right\}\right]\right] \\
& \times \frac{2 C_{f} K_{\text {struc }}}{\left(2 K_{\text {struc }}-\alpha_{\mathrm{LE}}\right)}
\end{aligned}
$$

in which we estimated the activation volume by $\left(l_{v} b d\right)$ where $d$ represents the length of thermal activation, and

$$
\begin{aligned}
\sigma_{y}^{\alpha}(T)= & {\left[\mu b \sqrt{A_{i i}\left(\rho_{o}^{\alpha}+\frac{K_{m} \gamma^{\alpha}}{b d_{m}}\right)}\right.} \\
& -\left[s_{0}^{*} \times \ln \left\{-\frac{k_{B} T}{F_{0}^{*}} \ln \left(\frac{\dot{\gamma}_{y}^{\alpha}}{\left.\left.\left.\left.\left(\rho_{o}^{\alpha}+\frac{K_{m} \gamma^{\alpha}}{b d_{m}}\right) b l_{v} \frac{k_{B} T}{h}\right)\right\}\right]\right]}\right.\right.\right. \\
\times & \frac{2 C_{f} K_{\text {struc }}}{\left(2 K_{\text {struc }}-\alpha_{\mathrm{LE}}\right)}
\end{aligned}
$$

\section{Independent estimation of parameters and their uncertainty}

A robust quantification of the glide energy barrier requires the estimation of the uncertainty of all the pre-assumed parameters in Eq. (14). We regard these parameters into two categories related to their uncertainties: the first parameters are atomistic fundamental quantities with low uncertainty such as $k_{B}$ and $b$. The second category corresponds to highuncertainty parameters that result from mesoscale stochastic processes such as dislocation jump frequency and dislocation-dislocation interactions. For these latter parameters, we identify the value ranges that have been reported in the literature.

The shear modulus $(\mu)$ is a material parameter with relatively low uncertainty, which we accounted for by considering the Reuss and Voigt [33] models as lower and upper bounds, respectively. Overall, the uncertainty of elastic constants has a minor secondary effect as demonstrated in Appendix A using the elastic constants reported for various metals [34].

Since it is difficult and time-consuming to quantify dislocation densities with experiments, their estimations carry a large uncertainty. Hence, we assume a range for the initial dislocation densities based on experimental reports for various metals. Mavlyutov et al. [35] studied the effect of annealing temperature on dislocation densities in ultrafine-grained aluminum and found values between $4 \times 10^{12}$ and $1.5 \times 10^{12} \mathrm{~m}^{-2}$ for annealing at room temperature and $423 \mathrm{~K}$, respectively. Similarly, Williamson and Smallman [36] estimated dislocation densities between $10^{11}$ and $10^{12} \mathrm{~m}^{-2}$ for different annealed FCC metals. Here, we assume an initial dislocation density $\left(\rho_{o}{ }^{\alpha}\right)$ along primary slip system between $1 \times 10^{8}-1 \times 10^{11} \mathrm{~m}^{-2}$, and $\Delta \rho_{y}{ }^{\alpha}$ (contribution from yielding) is calculated using Eq. (12) subject to the grain size of material. Typically, $\Delta \rho_{y}{ }^{\alpha}$ ranges between $5 \times 10^{12}$ and $1 \times 10^{10} \mathrm{~m}^{-2}$ for grain sizes between 1 and $250 \mu \mathrm{m}$ [35]. In this analysis, the lower bound of dislocation density will remain $1 \times 10^{8} \mathrm{~m}^{-2}$; however, the upper bound will be modified for every material subject to its grain size.

The self-interaction coefficient $\left(A_{i i}\right)$ in Eq. (9) has been extensively estimated through experiments and dislocation dynamics simulations. The results obtained by multiple authors [37-41] reported a range between 0.1 and 0.3 for various materials and even for hydrogen pre-charged samples [42]. Furthermore, Fivel et al. [38] reported that interaction coefficients do not show significant change with the dislocation density and stress. As a result, we consider an average interaction coefficient between 0.1 and 0.3 .

The line tension coefficient $\left(\alpha_{L E}\right)$ in Eq. (9) is related to the stress required to bow out and multiplicate dislocations. Szajewski et al. [43] investigated dislocation bow-out using molecular dynamics and quantified line tension coefficient in the range of 0.5 to 0.85 . Tabata et al. [44] studied the effect of flow stress on dislocation behavior in aluminum [111] single crystal, assuming that the bow-out is pinned with forest dislocation in dislocation walls and used the line-energy coefficient as 1 . Therefore, we assume that the line tension value should be in a range between 0.5 and 1.5. Furthermore, regarding the similitude coefficient $\left(K_{\text {struc }}\right)$ in Eq. (10), Sauzay and Kubin [24] showed that FCC metals follow the similitude relation under cyclic and monotonic loading. They demonstrated that the similitude coefficient under monotonic loading varies between 5 and 10 , which corresponds to the range employed in this study. 
Kocks et al. [18] bounded the profile parameters $p$ and $q$ in Eq. (3) between $0-1$ and 1-2, respectively. Their calculations for $\Delta G$ considered various values and concluded that $p=3 / 4$ and $q=4 / 3$ represent an adequate but not unique solution. Instead, Fleischer [14] derived $p=1 / 2$ and $q=2$ for a dislocation interacting with local obstacles creating a tetragonal distortion, while Mott and Nabarro [15] proposed a sinusoidal interaction potential between dislocation and a particle in precipitate-hardened material and derived values of $p=2 / 3$ and $q=3 / 2$. More recently, Dong [45] used molecular dynamics to derive a polynomial expression for a dislocation-point obstacle interaction mechanism that resulted in $p=2 / 3$ and $q=3 / 2$. Hence, we initially assume $p=2 / 3$ and $q=3 / 2$, but we will later consider other values in the range proposed by Kocks [18].

Finally, Sobie et al. [32] studied the role of obstacle spacing on glide activation energy and proposed a spacing in the order of tens of nm. Thus, we assume an equivalent range for our analysis between 1 and $50 \mathrm{~nm}$. Table 1 summarizes the ranges of all the parameters in Eq. (14) that were considered in the Monte Carlo analysis for evaluating $F_{0}$ and $s_{0}$. The references support that these parameters are unlikely to have values outside these ranges, but current epistemic uncertainty prevents us from making more precise estimations.

\section{Quantification of glide activation from yield stress data}

\section{Monte Carlo simulations}

To estimate the glide energy barrier parameters $\left(F_{0}\right.$ and $s_{0}$ ) and their uncertainty, we implement a Monte Carlo approach that fits Eqs. (14), (15) and (16) to yield stress as a function of temperature. The schematic of the process is shown in Fig. If or Eqs. (14). The analysis considers the ranges of parameters in Table 1 for the materials summarized in Table 2. The tabulated yield stress as a function of homologous temperature is shown in Fig. 2. These figures present a quasi-linear dependence of the yield stress with homologous temperature up to a value of 0.2 , at which point a plateau becomes apparent.

The plateau in the yield stress has been attributed [46-49] to dynamic strain aging (DSA) and is caused by the interference of impurities and solute atoms (e.g., carbon) with the mobility of dislocations [50]. Because the model does not have any special provision for modeling the interference of diffusing of point obstacles, we limit our analysis yielding at homologous temperatures below 0.2. Nevertheless, the analysis can still be used in models without the explicit provision of DSA, and Appendix B presents the estimates of $F_{0}$ and $s_{0}$ using yield data over full range of temperature. In this case, glide activation parameters are engineering approximations that could be dependent on the deformation rate.

For each Monte Carlo calculation, we employ a set of parameters randomly chosen within the ranges in Table 1 , while $F_{0}$ and $s_{0}$ were bounded between 0-5 eV and 1-500 $\mathrm{MPa}$, respectively. Each parameter was chosen assuming a flat distribution within the bounds of their intrinsic epistemic uncertainty. Furthermore, the fitting skill is taken into account and only those results with R-square above 0.8 are considered in the analysis.

\section{Results}

Figure 3 to Fig. 4 present the outcomes from the Monte Carlo analysis for different FCC metals and alloys. The results of $F_{0}$ and $s_{0}$ are further summarized in Table 3, which presents the mean and 95\%
Table 1 Summary of different scaling-level parameters

\begin{tabular}{|c|c|c|}
\hline \multicolumn{2}{|l|}{ Parameters } & \multirow{2}{*}{$\begin{array}{l}\text { Values } \\
1 \times 10^{8}-1 \times 10^{11} \mathrm{~m}^{-2}\end{array}$} \\
\hline Initial dislocation density $\left(\rho_{o}\right)[35,36]$ & & \\
\hline Average interaction coefficient $\left(A_{i i}\right)[37-41]$ & & $0.1-0.3$ \\
\hline Line energy $\left(\alpha_{L E}\right)[43,44]$ & & $0.5-1.5$ \\
\hline Similitude coefficient $\left(K_{\text {struc }}\right)[24]$ & & $5-10$ \\
\hline$K_{m}[26-29]$ & & $1-4$ \\
\hline Profile parameters $[6,14,15,18,45]$ & $p$ & $0-1$ \\
\hline & $q$ & $1-2$ \\
\hline Mean separation distance between obstacles $\left(l_{v}\right)$ [32] & & $1 \times 10^{-9}-50 \times 10^{-9} \mathrm{~m}$ \\
\hline
\end{tabular}




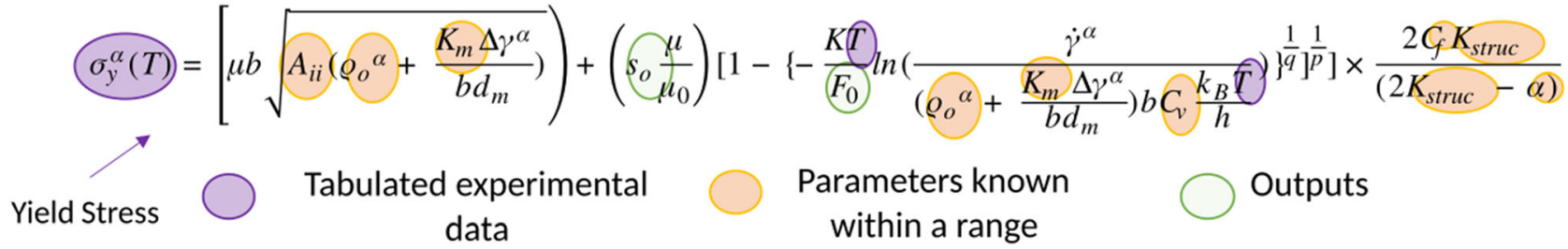

Inputs

\begin{tabular}{cc}
$\sigma_{y}^{\alpha}(\mathrm{MPa})$ & $\mathrm{T}(\mathrm{K})$ \\
\hline 50.96 & 19.86 \\
\hline 43.30 & 71.88 \\
\hline 35.44 & 139.43 \\
\hline 31.26 & 194.17 \\
\hline 30.53 & 299.56 \\
\hline 28.61 & 400.00
\end{tabular}
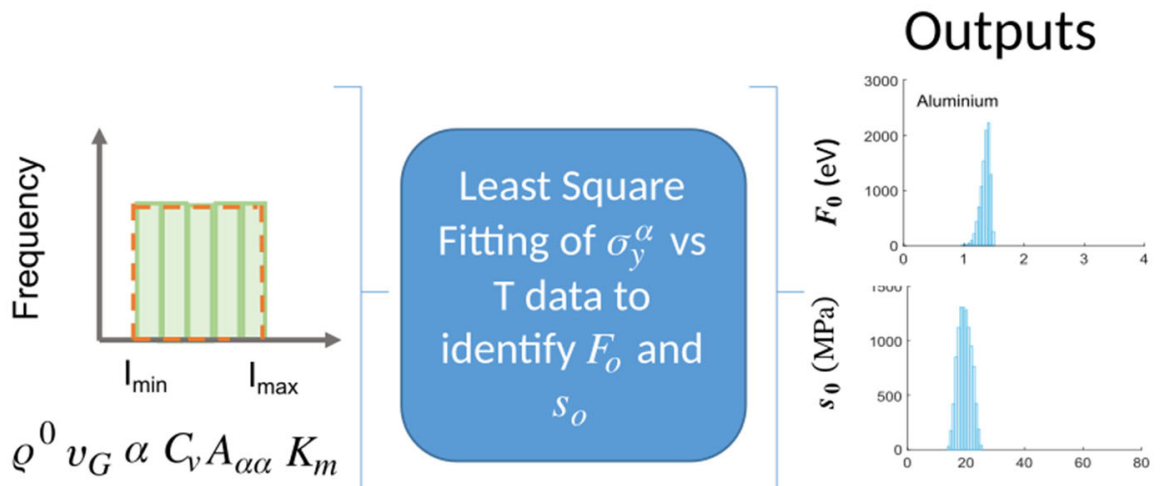

Figure 1 Schematic of Monte Carlo approach to estimate $F_{0}$ and $s_{0}$.

Table 2 Summary of materials and their properties used in Monte Carlo analysis. The SFE values are approximations that carry significant uncertainty (e.g., $25 \%$ [57])

\begin{tabular}{|c|c|c|c|c|c|c|c|}
\hline Materials & $\begin{array}{l}\text { Annealing } \\
\text { temp. }[\mathrm{K}]\end{array}$ & $\begin{array}{l}\text { Mean grain dia. } \\
\text { (d) }[\mu \mathrm{m}]\end{array}$ & $\begin{array}{l}\text { Purity } \\
\%\end{array}$ & $\begin{array}{l}\text { Strain rate } \\
\mathrm{s}^{-1}\end{array}$ & $\begin{array}{l}\text { Melting point } \\
{[\mathrm{K}]}\end{array}$ & $\begin{array}{l}\text { Stress }\left(\sigma_{y}\right) @ 293 \mathrm{~K} \pm 2 \\
{[\mathrm{MPa}]}\end{array}$ & $\begin{array}{l}\mathrm{SFE} \\
{\left[\mathrm{mJm}^{-2}\right]}\end{array}$ \\
\hline Aluminum [51] & 573 & 27 & 99.975 & $6 \times 10^{-4}$ & 933.5 & 30 & $166[58]$ \\
\hline Copper [47] & 623 & 15 & 99.999 & $6 \times 10^{-4}$ & 1358.2 & 72 & 46 [59] \\
\hline Silver [52] & 1073 & 40 & 99.97 & $6 \times 10^{-4}$ & 1234.9 & 48 & $17[60]$ \\
\hline Nickel [46] & 866 & 45 & 99.85 & $5.1 \times 10^{-4}$ & 1728.2 & 83 & 120 [61] \\
\hline $\begin{array}{l}\text { Stainless steel } 304 \\
\text { [53] }\end{array}$ & 1344 & 90 & N/A & $3.3 \times 10^{-4}$ & $1672-1694$ & 222 & 18 [62] \\
\hline $\begin{array}{l}\text { Stainless steel } 316 \\
{[54]}\end{array}$ & 1423 & 65 & N/A & $1 \times 10^{-4}$ & $1663-1713$ & 255 & $78[62]$ \\
\hline $\begin{array}{l}\text { Cupro-Nickel } \\
\text { [55] }\end{array}$ & 866 & 35 & N/A & $5.1 \times 10^{-4}$ & 1444.2 & 149 & 92 [63] \\
\hline Al 2024-T4 [56] & - & 50 & N/A & $3 \times 10^{-3}$ & 928.16 & 345 & 110 [64] \\
\hline
\end{tabular}

confidence interval values computed from Monte Carlo distributions. A total of 10,000 calculations per material was sufficient to converge the results for $F_{0}$ and $s_{0}$ as demonstrated in Appendix C. Among all materials, $F_{0}$ results in values between 1 and $3 \mathrm{eV}$ indicating, as expected, weak point obstacles [2]. Notably, $s_{o}$ resulted in a wide range between 15 and $350 \mathrm{MPa}$ among all materials. Moreover, the average normalized variability for $F_{0}$ and $s_{0}$ is $65 \%$ and $96 \%$, respectively, which demonstrates that the former has lower intrinsic uncertainty than the latter.

To further explore the significance of the results, we compare $F_{0}$ and $s_{0}$ with the intrinsic SFE, which often carries two-digit uncertainty. Although the parameters may correlate better with the energy that a leading partial dislocation must overcome (i.e., unstable SFE), the uncertainty of these magnitudes is even higher. The results in Figure 5 demonstrate that there is no apparent correlation between $s_{0}$ and the 


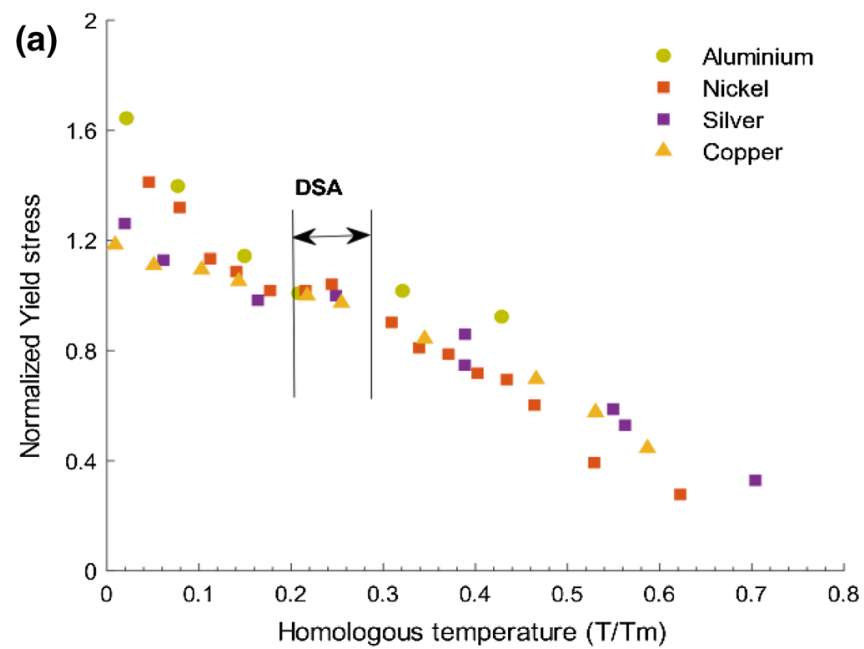

Figure 2 Normalized yield stress vs temperature for a polycrystalline metals $[46,47,51,52]$ for aluminum, copper, and silver, yield data corresponds to $0.5 \%$ strain but is $0.2 \%$ for nickel and $\mathbf{b}$ polycrystalline alloys [53-56]. The yield stress was

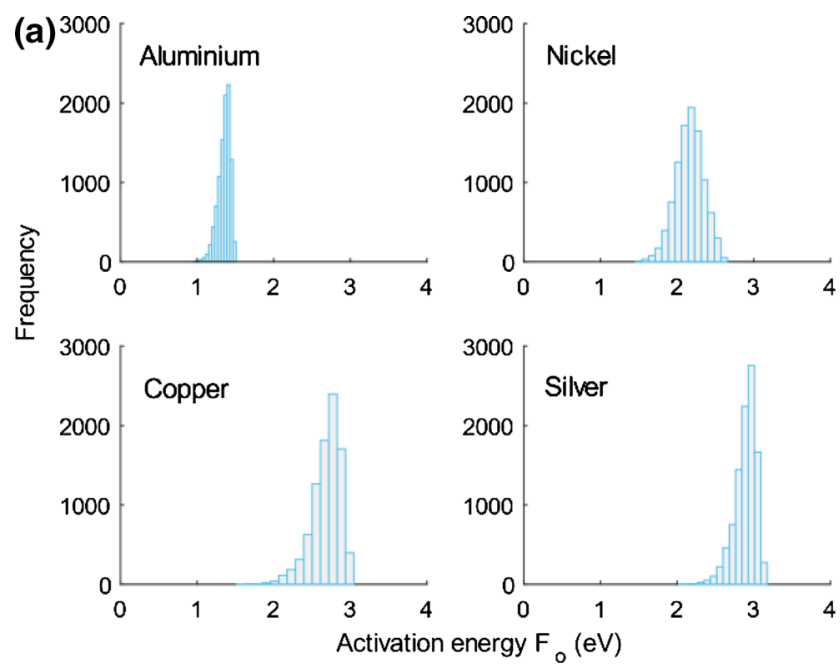

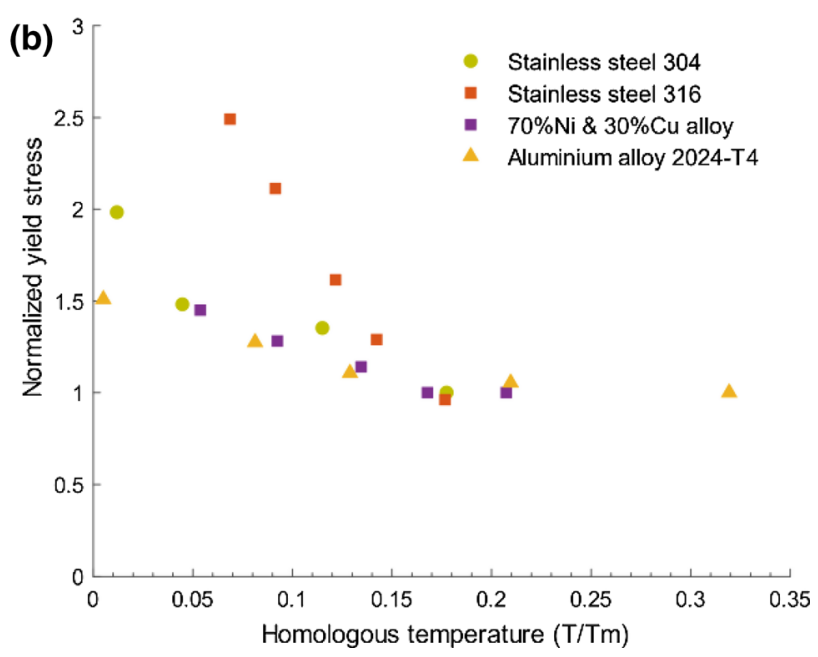

reported at $0.2 \%$ strain for all alloys. The normalization factor corresponds to the yield stress at room temperature. We consider each of the strain values as reported in experimental data in our analysis with Eq. (14).

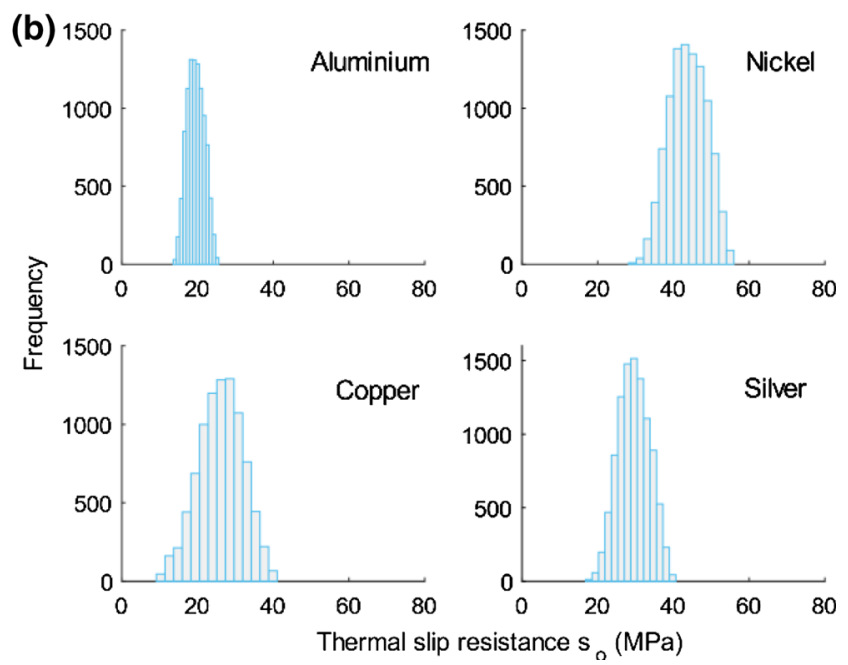

Figure 3 a Glide activation energy and $\mathbf{b}$ thermal slip resistance of aluminum, nickel, copper, and silver.

SFE. On the contrary, the activation energy presents an inverse proportionality with the SFE that can be parameterized as:

$F=F i-a * S F E$

with $F i=2.6( \pm 0.3), a=0.0067( \pm 0.0031)$. The relation between the SFE and $F_{0}$ was indeed alluded by Kocks for FCC metals [20] and can be used to obtain a firstorder estimation of $F_{0}$ when limited experimental data are available. The value of Eq. (17) is further underpinned by the lower intrinsic uncertainty of $F_{0}$, which suggests that limited experimental data should be used to estimate $s_{0}$ before refining the estimations of $F_{0}$.

\section{Effects of solute concentration and crystallographic orientation}

Continuing with the analysis of thermal stress, we recall the work from Wille et al. [65], who studied the effect of solute concentration on activation energy parameters in $\mathrm{Cu}-\mathrm{Mn}$ single crystal oriented for single slip. Their analysis used an empirical relation for the activation volume to quantify the sensitivity of activation energy and thermal stress to solute 

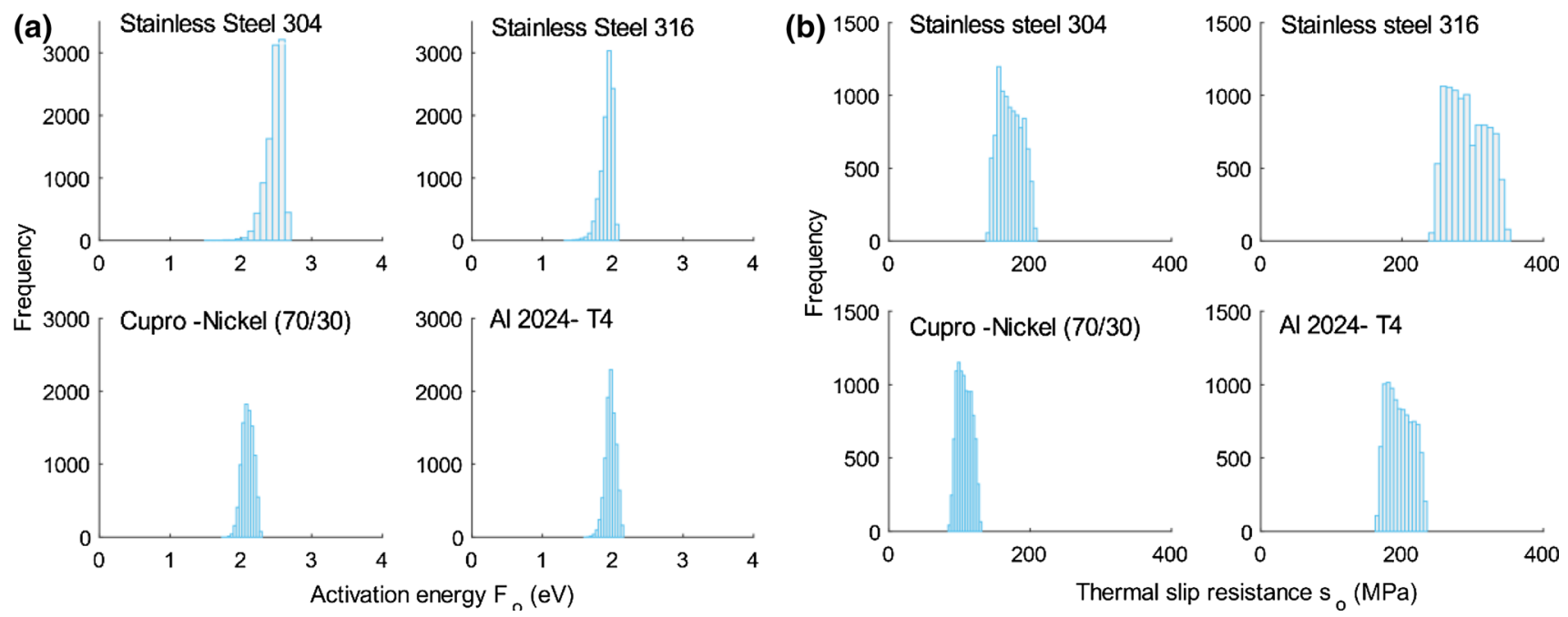

Figure 4 a Glide activation energy and b thermal slip resistance of SS 304, SS316, Cupro-Nickel, and Al $2024-\mathrm{T} 4$.

Table 3 Mean values and $95 \%$ confidence interval of $F_{0}$ and $s_{0}$ computed for pure metals and alloys

\begin{tabular}{lcc}
\hline Material & Activation energy 'eV' & Thermal slip resistance 'MPa' \\
\hline Aluminum & $1.3 \pm 0.3$ & $17.6 \pm 6.4$ \\
Nickel & $2.2 \pm 0.36$ & $43.8 \pm 9.4$ \\
Copper & $2.7 \pm 0.21$ & $26.1 \pm 12.8$ \\
Silver & $2.9 \pm 0.13$ & $29.6 \pm 9.1$ \\
Stainless steel 304 & $2.4 \pm 0.1$ & $172 \pm 27$ \\
Stainless steel 316 & $1.9 \pm 0.07$ & $292 \pm 43$ \\
Cupro-Nickel & $2.1 \pm 0.09$ & $107 \pm 17$ \\
Al 2024-T4 & $1.97 \pm 0.08$ & $197 \pm 26$ \\
Stainless steel 310 s & $2.06 \pm 0.08$ & $303 \pm 49$ \\
Cu- 7.6\%Mn & $1.86 \pm 0.04$ & $62.9 \pm 1.8$ \\
Aluminum single crystal & $1.38 \pm 0.28$ & $4.75 \pm 0.35$ \\
Nickel single crystal & $1.93 \pm 0.15$ & $26.2 \pm 1.6$ \\
Copper single crystal & $2.39 \pm 0.4$ & $4.7 \pm 1.2$ \\
\hline
\end{tabular}

concentration. To validate our approach, we consider the shear stress data at different temperatures from Wille et al. [65] (as shown in Appendix D) to compute the activation energy parameters. Figure 6 presents the effect of solute concentration on glide activation and thermal stress of $\mathrm{Cu}-\mathrm{Mn}$ alloy with a $95 \%$ confidence interval. Our results agree with the trends from Wille et al. [65] and demonstrate that an increase in solute concentration increases primarily the thermal stress rather than the activation energy. We highlight that our analysis does not require the empirical relation proposed by Wille et al. [65], but fully relies on physics-based mechanisms parameterized independently.

Further validation proceeds from an analysis of a single crystal oriented for single slip, which does not promote cross-slip at low plastic strain amplitude.
Hence, to ascertain that the estimated activation energies relate indeed to the gliding process rather than cross-slip, we consider aluminum, nickel, and copper single crystals [66-68]. Figure 7 compares the activation energy for these single crystals (SC) and polycrystals (PC); the overlapping of activation energies between single- and polycrystals supports our methodology. These results also highlight the variability conveyed by polycrystals. A second consideration is that the thermal stresses in polycrystalline analysis seem consistently higher than that in single crystals. One source for such effect is their difference in the level of impurities as shown before. (These materials are effectively not pure when considering the thermal stress.)

Another aspect that requires consideration is the effect of grain size on yield stress [69], which may 
Figure 5 Correlation between glide activation and stacking fault energy of different FCC metals and alloys. The experimental data for SS $310 \mathrm{~s}$ alloy are given in Appendix D.

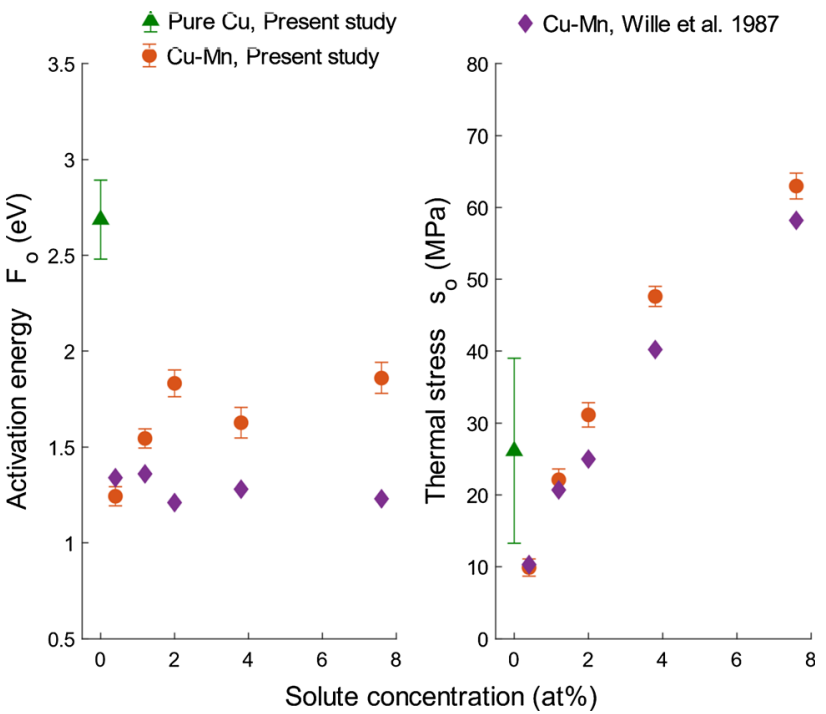

Figure 6 Activation energy and thermal stress of $\mathrm{Cu}-\mathrm{Mn}$ alloy with different solute concentrations. Error bars correspond to a $95 \%$ confidence interval.

affect the estimation of the glide parameters. Figure 8 presents the effect of different grain sizes on activation energy parameters. The overlapping of results in Fig. 8 shows that glide activation energy and thermal stress are not significantly influenced by the grain size. This further validates the incorporation of the grain size effect in Eq. (14).

\section{Considerations for different activation energy formulations}

We now estimate the activation energy parameters with a similar analysis but considering different $p$ and $q$ values for Eq. (3). Figure 9 demonstrates that the choice of $p$ and $q$ can influence the values for $F_{0}$ and $s_{0}$. Moreover, the average quality of the leastsquare fitting represented by the $R$ coefficient in Table 4 saturates for $p>2 / 3$ and $q<3 / 2$. Hence, we support Kocks [20] recommendation that $\mathrm{p}$ and $\mathrm{q}$ should be fixed between $2 / 3-1$ and $1-3 / 2$, respectively, and only $F_{0}$ and $s_{0}$ should be adjusted to match experimental data. This strategy is likely to work due to the linear nature of the yield stress data below 0.2 homologous temperature, which suggests that the use of four parameters overdetermines the problem.

Next, we perform a similar analysis considering the parameterization of Gibbs energy in Eqs. (4) and (5) The results in Fig. 10a show that the Helmholtz free energy is almost independent of the SFE, while the thermal activation length scale correlates with the SFE. Similar to the results for Eq. (3) in Fig. 5, 


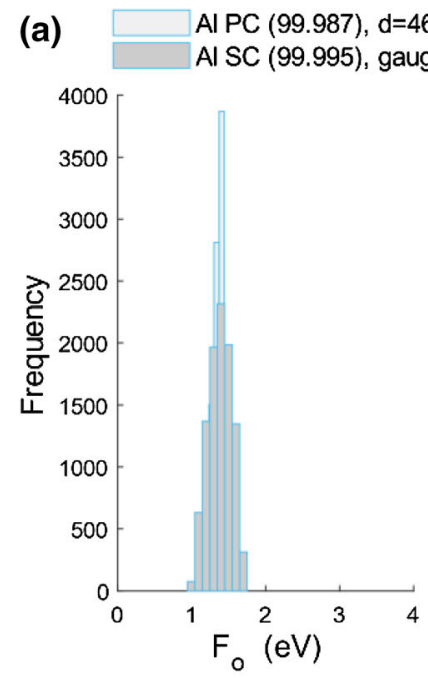

Al PC (99.987), d=46 $\mu \mathrm{m}$, Carreker (1957)

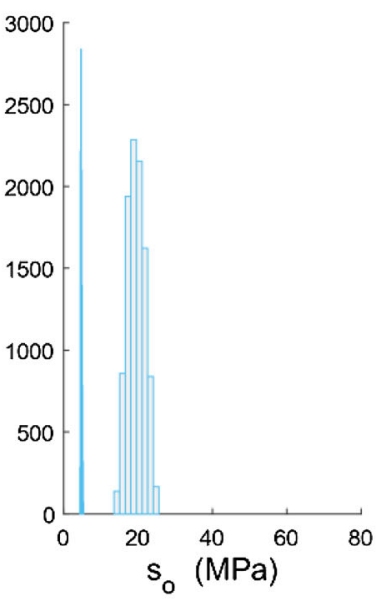

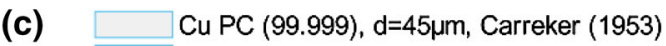
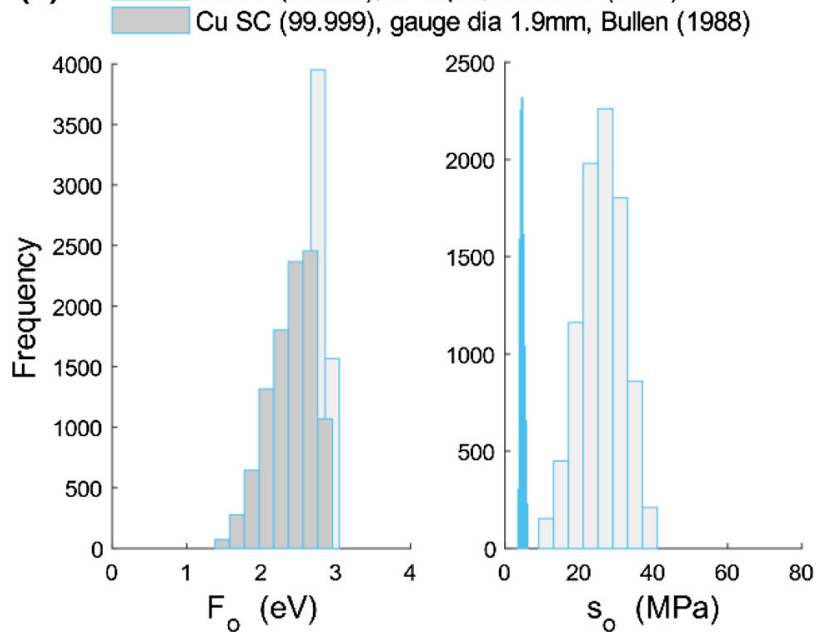

Figure 7 Activation energy and thermal stress of a aluminum, b nickel, and c copper single (SC) and polycrystals (PC). Experimental data of polycrystals [47] are shown in Fig. 2, and

Fig. 10b demonstrates that the pinning energy correlates with the SFE, but not the thermal stresses.

\section{Discussion}

This study characterized the dislocation glide energy barrier in FCC metals and alloys by combining physics-based crystal plasticity models and parameter uncertainty. We considered three formulations for the Gibbs free energy as a function of the effective stress, which was computed using parameters that were estimated independently. The analysis used least-square fitting of experimental data to determine only two parameters at a time rather than multiple

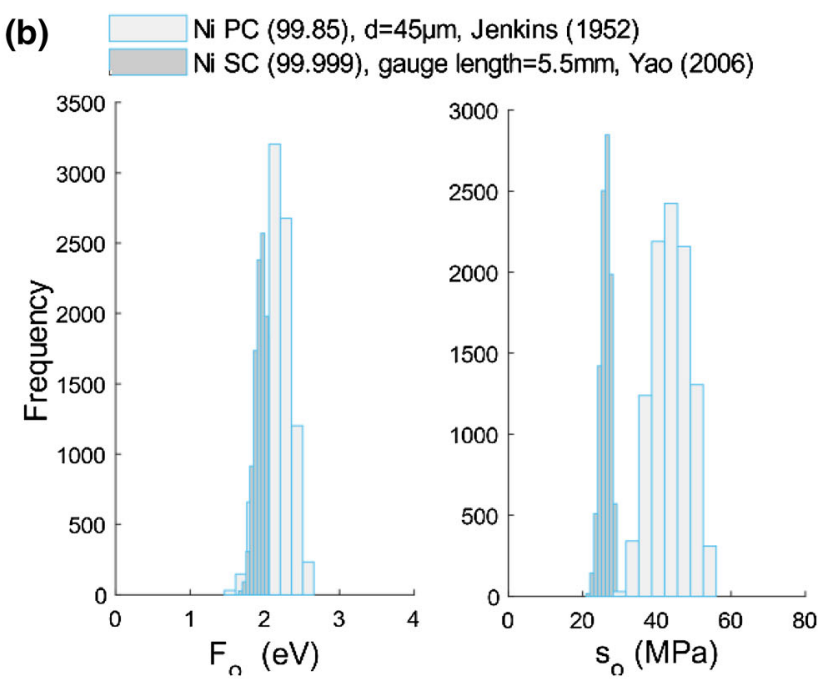

data for single crystals [66-68] are given in Appendix D. The dimensions correspond to the grain size for polycrystals and crystal size for single crystals.

coefficients $[9,65]$. As a result, we mitigated the spurious cancelation of error among parameters and we were able to estimate the uncertainty of the activation energy parameterization.

The comparison among Gibbs free energy formulations showed that Kocks approach (Eqs. (14)) provides the best results when fitting the yield stress dependence on temperature, even when parameters $p$ and $q$ were fixed. Equations (15) and (16) represent fixed linear and exponential dependence of yield stress on temperature, respectively, which limits their applicability in fitting all materials in Figure 5 and Table 5 further compares the fitting quality from using Eqs. (14), (15) and (16) by presenting the average R-square coefficient from all materials and 

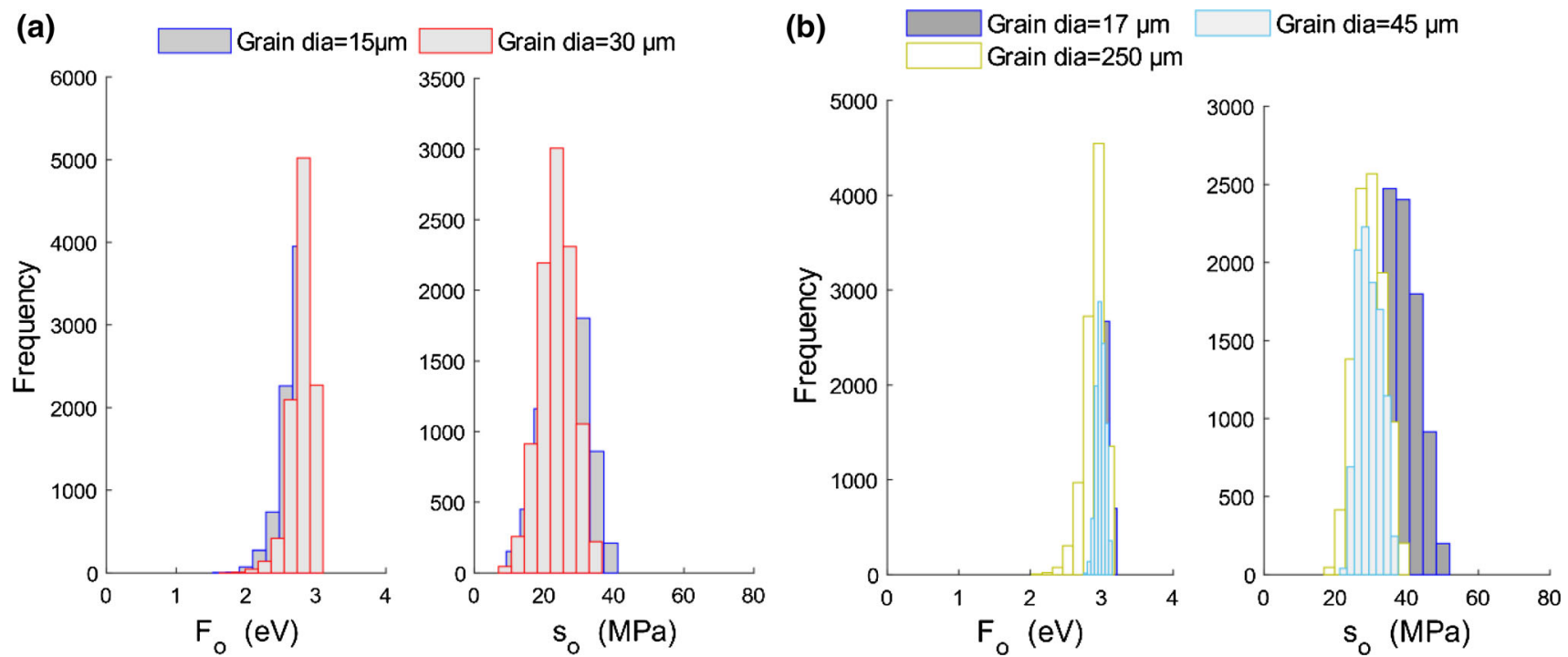

Figure 8 Effect of grain size on glide activation energy and thermal stress in a copper $\mathbf{b}$ silver. The upper bound of the dislocation density range is different for each case subject to the grain size.
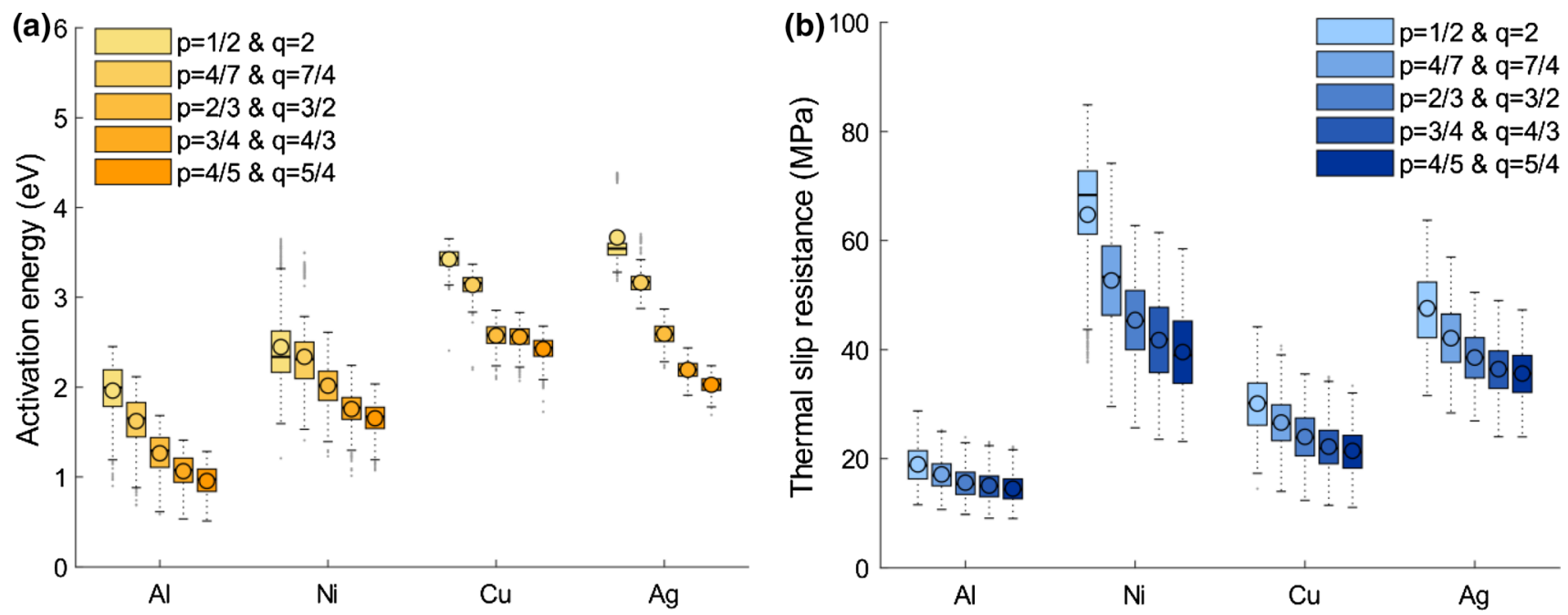

Figure 9 Effect of different $p$ and $q$ values on a glide activation energy and $\mathbf{b}$ thermal slip resistance of different FCC metals.

Table 4 Effect of $p$ and $q$ on average $R$-square computed from fitting results of Fig. 9

\begin{tabular}{|c|c|c|c|c|c|}
\hline & $p=1 / 2$ and $q=2$ & $p=4 / 7$ and $q=7 / 4$ & $p=2 / 3$ and $q=3 / 2$ & $p=3 / 4$ and $q=4 / 3$ & $p=4 / 5$ and $q=5 / 4$ \\
\hline $\mathrm{Al}$ & 0.83 & 0.86 & 0.93 & 0.96 & 0.97 \\
\hline $\mathrm{Ni}$ & 0.83 & 0.90 & 0.96 & 0.96 & 0.96 \\
\hline $\mathrm{Cu}$ & 0.88 & 0.89 & 0.89 & 0.91 & 0.91 \\
\hline $\mathrm{Ag}$ & 0.83 & 0.85 & 0.91 & 0.97 & 0.98 \\
\hline Total Average & 0.84 & 0.87 & 0.93 & 0.95 & 0.95 \\
\hline
\end{tabular}

simulations. The results demonstrate a better fitting with Eq. (14) as compared to other formulations. Hence, our analysis supports the quantification of
Gibbs free energy using Kocks formulation (Eqs. (14) with profile parameters $p$ and $q$ fixed in the ranges between $2 / 3-1$ and $1-3 / 2$, respectively. 


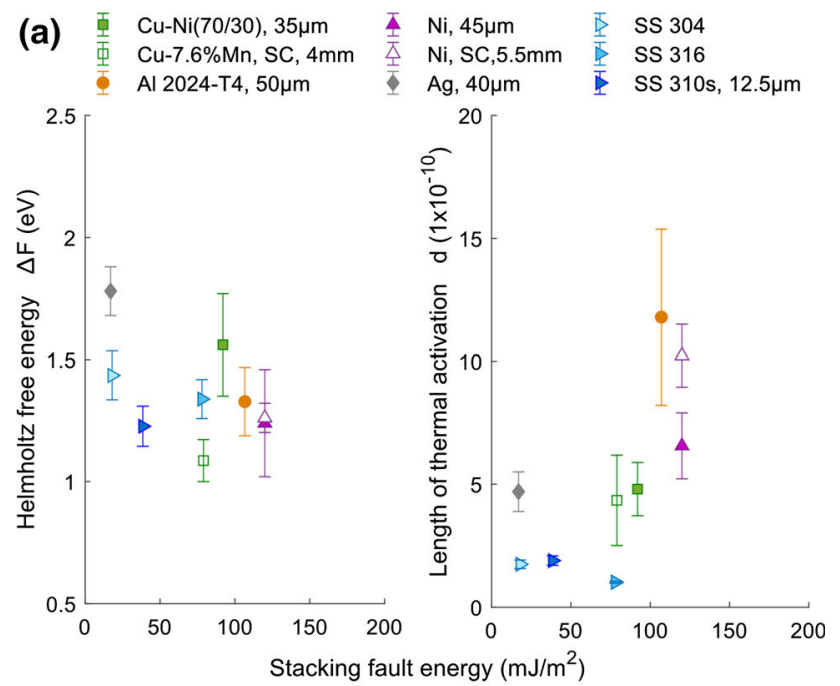

However, the relation found between the activation energy and the intrinsic SFE in Eq. (17) can be employed as a first-order estimation of $F_{0}$. This estimation is independent of $s_{0}$, which can be subsequently quantified by fitting the response to the available experimental data. This methodology provides an independent and robust estimation of the glide activation parameters and mitigates spurious errors.

Our analysis has focused on yield stress at low temperatures due to the lack of a special provision of DSA in the crystal plasticity model. $F_{0}$ and $s_{0}$ can still be calculated using the entire temperature range as shown in Appendix B, but we regard this calculation as an engineering approximation that obscures the fact that $s_{o}$ should change due to DSA. Indeed, our work has shown that $s_{0}$ depends strongly on the solute concen-

(b) $\mathrm{Cu}-\mathrm{Ni}(70 / 30), 35 \mu \mathrm{m}$ 更 $\mathrm{Cu}-7.6 \% \mathrm{Mn}, \mathrm{SC}, 4 \mathrm{~mm}$

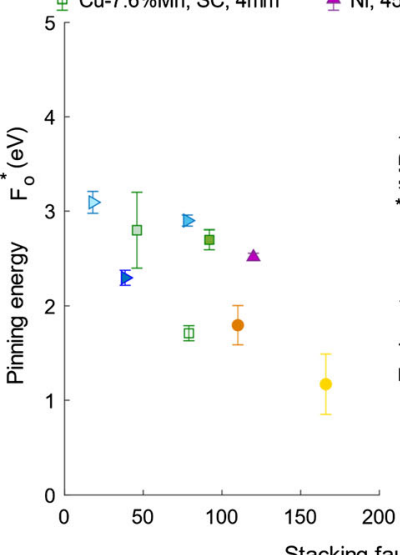

Stacking fault energy $\left(\mathrm{mJ} / \mathrm{m}^{2}\right)$

Figure 10 Estimation of glide parameters for a Eq. (15) and b Eq. (16).

Table 5 Comparison of average $R$-square between different formulations computed from fitting results of Fig. 5 and Fig. 10

\begin{tabular}{llll}
\hline Formulations & Equation (14) & Equation (15) & Equation (16) \\
\hline$R$-square & 0.86 & 0.79 & 0.65 \\
\hline
\end{tabular}

Multiscale crystal plasticity models are usually calibrated without sufficient data to quantify all parameters independently. In practical terms, a spurious increase $F_{0}$ can be counteracted by reducing $s_{0}$ to match the same experimental data. This makes it difficult to estimate both parameters independently and affects the model prediction (e.g., when used for temperatures and deformation rates outside the calibration database). tration. Hence, small temporary changes in solute concentrations around dislocations due to DSA should affect the effective $s_{0}$. This analysis further suggests that DSA can be modeled by introducing a dependence for $s_{0}$ on the effective solute content around dislocations, which would depend on the deformation rate, temperature, and diffusivity of species.

Finally, our approach relied on experimental data readily available in the literature to predict the glide activation energy in monolithic FCC metals with weak point obstacles. Future efforts can further explore the extension of the analysis to metals with medium- and high-strength obstacles. These approaches should add additional strengthening mechanisms to the athermal stress as well as reconsider the dependences of the parameters involved.

\section{Conclusions}

A physics-based predictive approach is presented to estimate the dislocation glide energy barrier in metals while considering parameter uncertainties independently. We explored the roles of weak point obstacles, dislocation strengthening, and grain size to predict the dependence of yield stress on the temperature in annealed metallic materials.

We employed Monte Carlo simulations to fit the formulations to experimental data and quantify glide activation parameters and their intrinsic epistemic uncertainty. Our calculations identified the effect of impurities on solid solution strengthening and found a correlation between the glide activation energy and the SFE. 
Our analysis suggests that Kocks parameterization of the Gibbs free energy can estimate nonlinear yield stress responses, even if parameters $p$ and $q$ are fixed between $2 / 3-1$ and $1-3 / 2$, respectively. Although the activation energy and thermal stress depend on $p$ and $q$, the fitting quality does not in this range. Furthermore, we proposed the use of the relation between the glide activation energy and the SFE to estimate multiscale model parameters when limited experimental data are available for calibration.

\section{Acknowledgements}

The authors are grateful for the support of The Punjab Educational Endowment Fund (PEEF) for funding the project.

\section{Declarations}

Conflict of interest The authors declare that they have no known competing financial interests or personal relationships that could have appeared to influence the work reported in this paper.

Open Access This article is licensed under a Creative Commons Attribution 4.0 International License, which permits use, sharing, adaptation, distribution and reproduction in any medium or format, as long as you give appropriate credit to the original author(s) and the source, provide a link to the Creative Commons licence, and indicate if changes were made. The images or other third party material in this article are included in the article's Creative Commons

Table 6 Shear modulus for different FCC metals and alloys

\begin{tabular}{|c|c|c|c|c|c|}
\hline \multirow[t]{3}{*}{ Materials } & \multicolumn{4}{|l|}{ Shear modulus } & \multirow[t]{3}{*}{$b\left[10^{-10} \mathrm{~m}\right]$} \\
\hline & \multicolumn{2}{|l|}{ Reuss model } & \multicolumn{2}{|l|}{ Voigt model } & \\
\hline & $\mu(300 \mathrm{~K})[\mathrm{GPa}]$ & $\mu_{0}(0 \mathrm{~K})[\mathrm{GPa}]$ & $\mu(300 \mathrm{~K})[\mathrm{GPa}]$ & $\mu_{0}(0 \mathrm{~K})[\mathrm{GPa}]$ & \\
\hline Aluminum & $25.9[34]$ & $29.1[34]$ & $26.2[33]$ & $29.4[33]$ & $2.86[18]$ \\
\hline Nickel & $78.2[34]$ & $84.7[34]$ & $94.2[33]$ & $101[33]$ & $2.49[18]$ \\
\hline Copper & $41.7[34]$ & $43.5[34]$ & $54.6[33]$ & $59.3[33]$ & $2.56[18]$ \\
\hline Silver & $25.4[34]$ & $28.4[34]$ & $33.5[33]$ & $37.5[33]$ & $2.89[18]$ \\
\hline Stainless steel 304 & $77.3[70]$ & $82.1[70]$ & - & - & $2.58[2]$ \\
\hline Stainless steel 316 & $75.1[70]$ & $81.0[70]$ & - & - & $2.58[71]$ \\
\hline Cupro-Nickel & $57.0[72]$ & $60.6[72]$ & - & - & $2.56[18]$ \\
\hline AA 2024-T4 & $25.9[73]$ & $29.2[73]$ & - & - & $2.87[18]$ \\
\hline
\end{tabular}
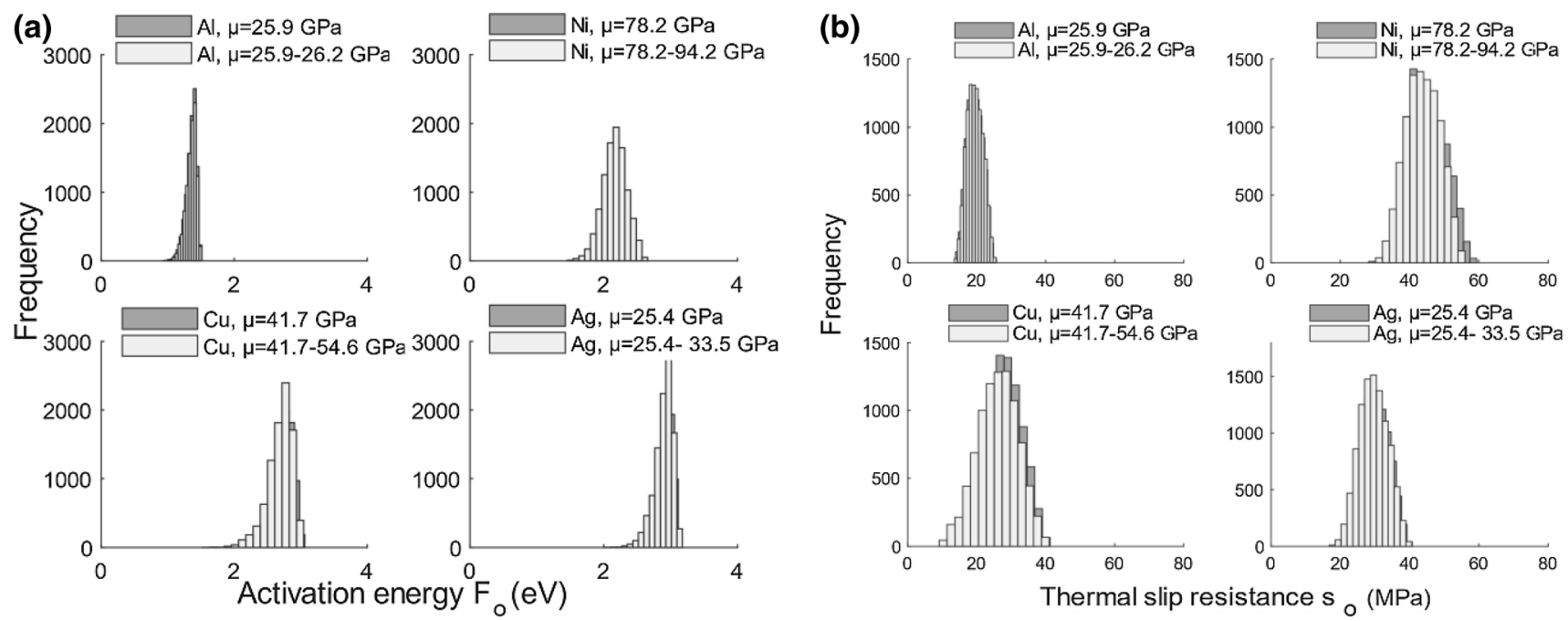

Figure 11 Effect of shear modulus range on a activation energy and $\mathbf{b}$ thermal stress. For the shear modulus range, the Reuss model is used as a lower bound and Voigt model as an upper bound. 
licence, unless indicated otherwise in a credit line to the material. If material is not included in the article's Creative Commons licence and your intended use is not permitted by statutory regulation or exceeds the permitted use, you will need to obtain permission directly from the copyright holder. To view a copy of this licence, visit http://creativecommons.org/licen ses/by $/ 4.0 /$.

\section{Appendix A: Effect of shear modulus range on $F_{o}$ and $s_{o}$}

Table 6 presents the shear modulus and Burgers vector for different metals and alloys used in the current analysis. Figure 11 shows that glide activation energy and thermal stresses for different FCC metals are less sensitive to the uncertainty underlying shear modulus.

Table 7 Mean values and 95\% confidence interval of activation energy $\left(F_{0}\right)$ and thermal slip resistance $\left(s_{0}^{t}\right)$ computed using the yield data at full range of temperature

\begin{tabular}{llcl}
\hline Materials & $F_{\mathrm{o}}(\mathrm{eV})$ & $s_{\mathrm{o}}(\mathrm{MPa})$ & $R$-square \\
\hline Aluminum & $1.88 \pm 0.2$ & $20.64 \pm 2.4$ & 0.87 \\
Nickel & $2.98 \pm 0.3$ & $43.34 \pm 10.5$ & 0.81 \\
Copper & $3.77 \pm 0.15$ & $16.4 \pm 5.8$ & 0.69 \\
Silver & $3.75 \pm 0.4$ & $28.8 \pm 8.6$ & 0.93 \\
\hline
\end{tabular}

Figure 13 Shear stress data at different temperatures for a aluminum, nickel, and copper single crystals [66-68], b $\mathrm{Cu}-\mathrm{Mn}$ with different solute concentrations [65], c stainless steel $310 \mathrm{~s}$ [74].
Appendix B: Estimation of $F_{o}$ and $s_{0}$ using yield data at entire range of temperature

In this section, Table 7 presents the results for $F_{0}$ and $\mathrm{s}_{\mathrm{o}}$ computed by fitting Eq. (14) to the entire temperature range. The plateau in yield stress due to DSA reduces the quality of the fitting as demonstrated by

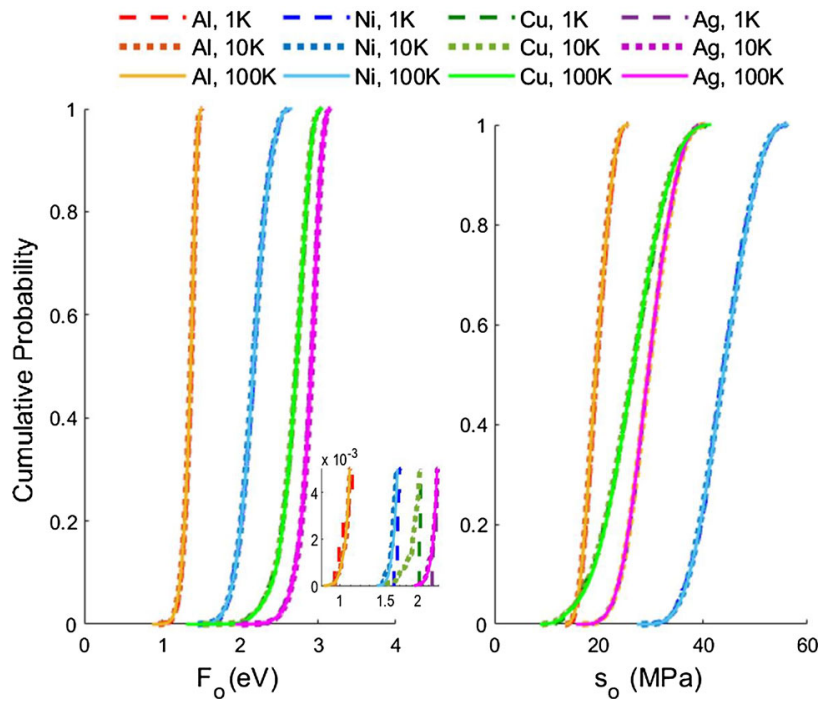

Figure 12 Empirical cumulative probability plots comparing the Monte Carlo results of Fo and so for different FCC metals after $1 \times 10^{3}, 1 \times 10^{4}$, and $1 \times 10^{5}$ iterations. The results demonstrate that $1 \times 10^{4}$ and $1 \times 10^{5}$ are indistinguishable.
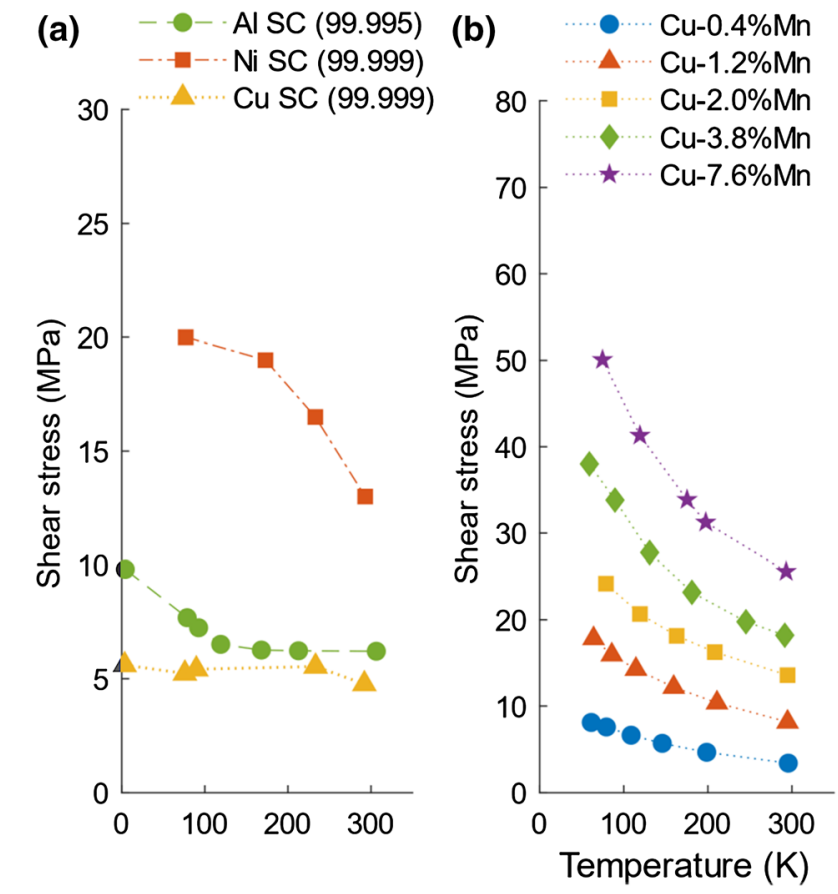

(c)

SS 310s

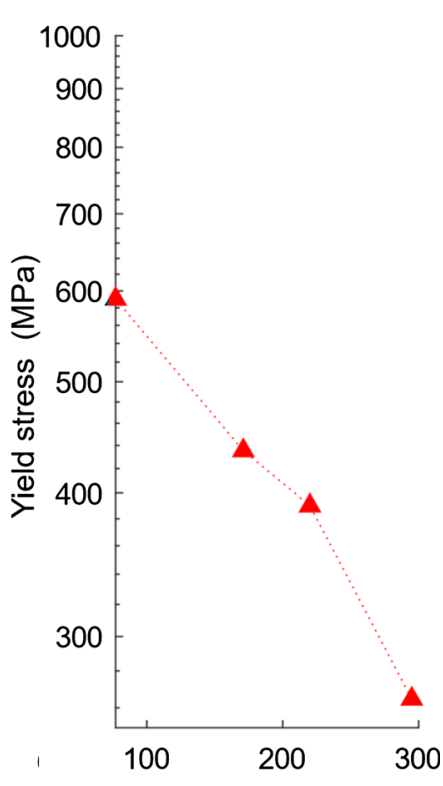


the R coefficient. Moreover, Eq. (14) does not have a provision for DSA, which means that we should expect $F_{0}$ and $\mathrm{s}_{\mathrm{o}}$ to be dependent on the deformation rate.

\section{Appendix C: Iterative convergence analysis}

This appendix evaluates the convergence of $F_{o}$ and $s_{o}$ with different number of iterations of the Monte Carlo analysis for different FCC metals. Figure 12 presents the empirical cumulative probability plots for the Monte Carlo results of $F_{\mathrm{o}}$ and $s_{\mathrm{o}}$ after $1 \times 10^{3}$, $1 \times 10^{4}$, and $1 \times 10^{5}$ iterations. These results demonstrate that $1 \times 10^{4}$ iterations are sufficient to achieve convergence.

\section{Appendix D: Experimental data used in the analysis}

Figure 13 shows the experimental data for aluminum, nickel, and $\mathrm{Cu}$ single crystals, $\mathrm{Cu}-\mathrm{Mn}$ single crystal, and stainless steel $310 \mathrm{~s}$, respectively. The data are used to calculate activation energy parameters shown in Fig. 5, Fig. 6, and Fig. 7.

\section{References}

[1] Krausz AS, Eyring H (1976) The reaction kinetics of plastic deformation. In: Deformation kinetics. John Wiley \& Sons, Inc, New York

[2] Frost HJ, Ashby MF (1982) Deformation mechanisms maps. Pergamon Press, New York

[3] Sobie C, Capolungo L, McDowell DL, Martinez E (2017) Thermal activation of dislocations in large scale obstacle bypass. J Mech Phys Solids 105:150-160. https://doi.org/10. 1016/j.jmps.2017.05.003

[4] Esteban-Manzanares G, Martínez E, Segurado J et al (2019) An atomistic investigation of the interaction of dislocations with Guinier-Preston zones in Al-Cu alloys. Acta Mater 162:189-201. https://doi.org/10.1016/j.actamat.2018.09.052

[5] Narayanan S, McDowell DL, Zhu T (2014) Crystal plasticity model for BCC iron atomistically informed by kinetics of correlated kinkpair nucleation on screw dislocation. J Mech Phys Solids 65:54-68. https://doi.org/10.1016/j.jmps.2014. 01.004

[6] Dong Y, Nogaret T, Curtin WA (2010) Scaling of dislocation strengthening by multiple obstacle types. Metall Mater Trans
A Phys Metall Mater Sci 41:1954-1960. https://doi.org/10. 1007/s11661-010-0229-Z

[7] Wille TH, Schwink C (1986) Precision measurements of critical resolved shear stress in CuMn alloys. Acta Metall 34:1059-1069. https://doi.org/10.1016/0001-6160(86)90216 $-6$

[8] Kothari M, Anand L (1998) Elasto-viscoplastic constitutive equations for polycrystalline metals: application to tantalum. J Mech Phys Solids 46:51-67. https://doi.org/10.1016/S002 2-5096(97)00037-9

[9] Balasubramanian S, Anand L (2002) Elasto-viscoplastic constitutive equations for polycrystalline FCC materials at low homologous temperatures. J Mech Phys Solids 50:101-126. https://doi.org/10.1016/S0022-5096(01)000229

[10] Krausz AS, Eyring H (1971) Chemical kinetics of plastic deformation. J Appl Phys 42:2382-2385. https://doi.org/10. $1063 / 1.1660552$

[11] Gibbs GB (1969) Thermodynamic analysis of dislocation glide controlled by dispersed local obstacles. Mater Sci Eng 4:313-328. https://doi.org/10.1016/0025-5416(69)90026-3

[12] Orowan E (1940) Problems of plastic gliding. Proc Phys Soc 52:8-22. https://doi.org/10.1088/0959-5309/52/1/303

[13] Seeger AK (1959) On the theory of radiation damage and radiation hardening. In: Proceedings of 2 nd united nations international conference on the peaceful uses of atomic energy. p 250

[14] Fleischer RL (1962) Solution hardening by tetragonal distortions: application to irradiation hardening in F.C.C. crystals. Acta Metall 10:835-842. https://doi.org/10.1016/00016160(62)90098-6

[15] Mott NF, Nabarro FRN (1948) Dislocation theory and transient creep. In: Report on the Bristol conference on strength of solids. Physical Society, pp 1-19

[16] Dunne FPE, Rugg D, Walker A (2007) Lengthscale-dependent, elastically anisotropic, physically-based hcp crystal plasticity: application to cold-dwell fatigue in Ti alloys. Int $\mathrm{J}$ Plast 23:1061-1083. https://doi.org/10.1016/j.ijplas.2006.10. 013

[17] Langer JS (2019) Statistical thermodynamics of crystal plasticity. J Stat Phys 175:531-541. https://doi.org/10.1007/ s10955-019-02221-7

[18] Kocks UF, Argon AS, Ashby MF (1975) Thermodynamics and Kinetics of Slip. Pergamon Press, Oxford

[19] Castelluccio GM, McDowell DL (2017) Mesoscale cyclic crystal plasticity with dislocation substructures. Int J Plast 98:1-26. https://doi.org/10.1016/j.ijplas.2017.06.002

[20] Kocks UF (2001) Realistic constitutive relations for metal plasticity. Mater Sci Eng A 317:181-187. https://doi.org/10. 1016/S0921-5093(01)01174-1 
[21] Guo YZ, Sun XY, Wei Q, Li YL (2017) Compressive responses of ultrafine-grained titanium within a broad range of strain rates and temperatures. Mech Mater 115:22-33. h ttps://doi.org/10.1016/j.mechmat.2017.07.015

[22] Sachs G (1929) Zur Ableitung einer Fließbedingung. Mitteilungen der deutschen Materialprüfungsanstalten. Springer, Berlin, Heidelberg, pp 94-97

[23] Franciosi P (1985) The concepts of latent hardening and strain hardening in metallic single crystals. Acta Metall 33:1601-1612. https://doi.org/10.1016/0001-6160(85)90154 $-3$

[24] Sauzay M, Kubin LP (2011) Scaling laws for dislocation microstructures in monotonic and cyclic deformation of FCC metals. Prog Mater Sci 56:725-784. https://doi.org/10.1016/ j.pmatsci.2011.01.006

[25] Nix WD, Greer JR, Feng G, Lilleodden ET (2007) Deformation at the nanometer and micrometer length scales: effects of strain gradients and dislocation starvation. Thin Solid Films 515:3152-3157. https://doi.org/10.1016/j.tsf.20 06.01 .030

[26] Hansen N (1987) The effect of grain size and strain on the tensile flow stress of quenched aluminum. Acta Metall 35:227-235. https://doi.org/10.1016/0001-6160(87)90230-6

[27] Ashby MF (1970) The deformation of plastically non-homogeneous materials. Philos Mag 21:399-424. https://doi. org/10.1080/14786437008238426

[28] Essmann U, Mughrabi H (1979) Annihilation of dislocations during tensile and cyclic deformation and limits of dislocation densities. Philos Mag A Phys Condens Matter, Struct Defects Mech Prop 40:731-756. https://doi.org/10.1080/ 01418617908234871

[29] Tabata T, Yamanaka S, Fujita H (1978) In situ deformation of the [111] aluminum single crystals observed by high voltage electron microscopy. Acta Metall 26:405-411. http s://doi.org/10.1016/0001-6160(78)90167-0

[30] van Liempt P, Bos C, Sietsma J (2016) A physically based yield criterion II. Incorporation of Hall Petch effect and resistance due to thermally activated dislocation glide. Mater Sci Eng A 652:7-13. https://doi.org/10.1016/j.msea.2015.11. 035

[31] Eyring $H$ (1935) The activated complex in chemical reactions. J Chem Phys 3:63-71. https://doi.org/10.1063/1. 1749604

[32] Sobie C, Capolungo L, McDowell DL, Martinez E (2017) Scale transition using dislocation dynamics and the nudged elastic band method. J Mech Phys Solids 105:161-178. h ttps://doi.org/10.1016/j.jmps.2017.05.004

[33] Ledbetter HM, Naimon ER (1974) Relationship between single-crystal and polycrystal elastic constants. J Appl Phys 45:66-69. https://doi.org/10.1063/1.1663019
[34] Varshni YP (1970) Temperature dependence of the elastic constants. Phys Rev B 2:3952-3958. https://doi.org/10.1103/ PhysRevB.2.3952

[35] Mavlyutov AM, Latynina TA, Murashkin MY et al (2017) Effect of annealing on the microstructure and mechanical properties of ultrafine-grained commercially pure Al. Phys Solid State 59:1970-1977. https://doi.org/10.1134/ S1063783417100274

[36] Williamson GK, Smallman RE (1956) III. Dislocation densities in some annealed and cold-worked metals from measurements on the X-ray Debye-Scherrer spectrum. Philos Mag 1:34-46. https://doi.org/10.1080/14786435608238074

[37] Kubin L, Devincre B, Hoc T (2008) Modeling dislocation storage rates and mean free paths in face-centered cubic crystals. Acta Mater 56:6040-6049. https://doi.org/10.1016/ j.actamat.2008.08.012

[38] Fivel M, Tabourot L, Rauch E, Canova G (1998) Identification through mesoscopic simulations of macroscopic parameters of physically based constitutive equations for the plastic behaviour of fcc single crystals. J Phys IV JP 8:151-158. https://doi.org/10.1051/jp4:1998819

[39] Devincre B, Hoc T, Kubin L (2008) Dislocation mean free paths and strain hardening of crystals. Science 320:1745-1748. https://doi.org/10.1126/science.1156101

[40] Schwartz J, Fandeur O, Rey C (2013) Numerical approach of cyclic behaviour of $316 \mathrm{LN}$ stainless steel based on a polycrystal modelling including strain gradients. Int $\mathrm{J}$ Fatigue 55:202-212. https://doi.org/10.1016/j.ijfatigue.2013.07.003

[41] Madec R, Devincre B, Kubin L et al (2003) The role of collinear interaction in dislocation-induced hardening. Science 301:1879-1882. https://doi.org/10.1126/science. 1085477

[42] Hachet G, Oudriss A, Barnoush A et al (2020) The influence of hydrogen on cyclic plasticity of $<001>$ oriented nickel single crystal. Part I: dislocation organisations and internal stresses. Int J Plast 126:102611. https://doi.org/10.1016/j.ij plas.2019.09.017

[43] Szajewski BA, Pavia F, Curtin WA (2015) Robust atomistic calculation of dislocation line tension. Model Simul Mater Sci Eng. https://doi.org/10.1088/0965-0393/23/8/085008

[44] Tabata T, Fujita H, Hiraoka MA, Miyake S (1982) The relationship between flow stress and dislocation behaviour in [111] aluminium single crystals. Philos Mag A Phys Condens Matter, Struct Defects Mech Prop 46:801-816. https://d oi.org/10.1080/01418618208236932

[45] Dong Y (2013) Coupled dislocation/dislocation and solute strengthening mechanisms in metal alloys. Ph.D. Dissertation, Brown University 
[46] Jenkins WD (1934) Digges TG (1952) Effect of temperature on the tensile properties of high-purity nickel. J Res Natl Bur Stand 48:313. https://doi.org/10.6028/jres.048.039

[47] Carreker RP, Hibbard WR (1953) Tensile deformation of high-purity copper as a function of temperature, strain rate, and grain size. Acta Metall. https://doi.org/10.1016/0001-6 160(53)90022-4

[48] Voyiadjis GZ, Song Y, Rusinek A (2019) Constitutive model for metals with dynamic strain aging. Mech Mater 129:352-360. https://doi.org/10.1016/j.mechmat.2018.12. 012

[49] Abd El-Azim ME (1997) Effect of dynamic strain ageing on the deformation behavior of Incoloy alloy MA956. Mech Mater 25:255-261. https://doi.org/10.1016/S0167-6636(97) 00005-7

[50] Nabarro FR (1948) Mechanical effects of carbon in iron. Physical society bristol conference Proc. Phys. Soc, London, pp 38-45

[51] Carreker RP, Hibbard WR (1957) Tensile deformation of aluminum as a function of temperature, strain rate, and grain size. Trans AIME J Met 1:1157-1163. https://doi.org/10.10 16/0001-6160(53)90022-4

[52] Carreker RP (1957) Tensile deformation of silver as a function of temperature, strain rate, and grain size. Trans AIME J Met 9:112-115. https://doi.org/10.1007/bf03398466

[53] Guntner CJ, Reed RP (1961) Mechanical properties of four austenitic stainless steels at temperatures between $300^{\circ}$ and $20^{\circ} \mathrm{K}$. Advances in cryogenic engineering. Springer, Boston, MA, pp 565-576

[54] Nickel Development Institute (1974) Materials for cryogenic service: Engineering properties of austenitic stainless seels. $\mathrm{h}$ ttps://www.nickelinstitute.org/media/1723/materialsforcryog enicservice engineeringpropertiesofausteniticstainlesssteel 4368 .pdf

[55] National Bureau of Standards (1952) Properties of metals at low temperatures. https://ia800809.us.archive.org/9/items/ci rcularofbureau520unse/circularofbureau520unse.pdf.

[56] Hickey CF Jr (1962) Mechanical properties of titanium and aluminium alloys at cryogenic temperatures. Watertown Arsenal Laboratories, Watertown, MA

[57] Muzyk M, Pakiela Z, Kurzydlowski KJ (2011) Ab initio calculations of the generalized stacking fault energy in aluminium alloys. Scr Mater 64:916-918. https://doi.org/10.10 16/j.scriptamat.2011.01.034

[58] Murr LE (1973) Twin boundary energetics in pure aluminium. Acta Metall 21:791-797. https://doi.org/10.1016/0 001-6160(73)90043-6

[59] Devlin JF (1974) Stacking fault energies of $\mathrm{Be}, \mathrm{Mg}, \mathrm{Al}, \mathrm{Cu}$, Ag, and Au. J Phys F Met Phys 4:1865-1882. https://doi. org/10.1088/0305-4608/4/11/011
[60] Li R, Lu S, Kim D et al (2016) Stacking fault energy of facecentered cubic metals: thermodynamic and ab initio approaches. J Phys Condens Matter. https://doi.org/10.1088/ 0953-8984/28/39/395001

[61] Carter CB, Holmes SM (1977) The stacking-fault energy of nickel. Philos Mag 35:1161-1171. https://doi.org/10.1080/ 14786437708232942

[62] Schramm RE, Reed RP (1975) Stacking fault energies of seven commercial austenitic stainless steels. Metall Trans A 6:1345-1351. https://doi.org/10.1007/BF02641927

[63] Wang ZY, Han D, Li XW (2017) Competitive effect of stacking fault energy and short-range clustering on the plastic deformation behavior of $\mathrm{Cu}-\mathrm{Ni}$ alloys. Mater Sci Eng A 679:484-492. https://doi.org/10.1016/j.msea.2016.10.064

[64] Kritzinger S, Dobson PS, Smallman RE (1967) The influence of a dilute magnesium addition on the growth ant shrinkage of dislocation loops in aluminium. Philos Mag 16:217-229. https://doi.org/10.1080/14786436708229735

[65] Wille TH, Gieseke W, Schwink CH (1987) Quantitative analysis of solution hardening in selected copper alloys. Acta Metall 35:2679-2693. https://doi.org/10.1016/0001-6160(8 7) $90267-7$

[66] Mukherjee AK, Mote JD, Dorn JE (1965) Strain hardening of single aluminum crystals during polyslip. Lawrence Berkeley national laboratory. Berkeley, California. Report \#: UCRL-11888. https://escholarship.org/uc/item/2523939t

[67] Yao Z, Schäublin R, Spätig P, Victoria M (2005) The tensile properties of irradiated $\mathrm{Ni}$ single crystals and their temperature dependence. Philos Mag 85:745-755. https://doi.org/ 10.1080/14786430412331319947

[68] Bullen FP, Mck. Cousland S (1968) The temperature dependence of the flow stress of copper single crystals. Phys Status Solidi 27:501-512. https://doi.org/10.1002/pssb. 19680270205

[69] Hall EO (1951) The deformation and ageing of mild steel: II characteristics of the Lüders deformation. In: Proceedings of the physical society. Section B. pp 742-747

[70] Ledbetter HM (1981) Stainless-steel elastic constants at low temperatures. J Appl Phys 52:1587-1589

[71] Lindgren LE, Hao Q, Wedberg D (2017) Improved and simplified dislocation density based plasticity model for AISI 316 L. Mech Mater 108:68-76. https://doi.org/10.1016/ j.mechmat.2017.03.007

[72] Reed Richard P.; Mikesell RP (1967) Low temperature mechanical properties of copper and selected copper alloys. National Bureau of Standards, United States Department of Commerce. https://nvlpubs.nist.gov/nistpubs/Legacy/MON O/nbsmonograph101.pdf.

[73] Gault C, Dauger A, Boch P (1977) Variations of the elastic constants of aluminium-magnesium single crystals with 
guinier-preston zones. Phys Status Solidi 43:625-632. http s://doi.org/10.1002/pssa.2210430233

[74] Abraham DP, Altstetter CJ (1995) The effect of hydrogen on the yield and flow stress of an austenitic stainless steel. Metall Mater Trans A 26:2849-2858. https://doi.org/10.100 7/BF02669643
Publisher's Note Springer Nature remains neutral with regard to jurisdictional claims in published maps and institutional affiliations. 